\title{
Resolução alternativa de conflitos na área de saúde: derivação da análise econômica de processos da competência dos Juizados Especiais na Seção Judiciária do Ceará
}

Alternative dispute resolution in public health: economic analysis of litigation in Federal Small Claims Courts of Ceará

\section{Dartanhan Vercingetórix de Araújo e Rocha}

Juiz da 9a Vara Federal do Ceará. Coordenador da Conciliação na Seção Judiciária do Ceará. Especialista em Direito e Processo Administrativos (UNIFOR). Especialista em Processo Civil (ESMEC). Membro do Comitê Interinstitucional de Enfrentamento ao Tráfico de Pessoas do Ceará. Membro de Turma Recursal na Seção Judiciária do Ceará.

Resumo: Objetivo: Aquilatar viabilidade na implementação de mecanismo de resolução alternativa de disputas na área da saúde, por meio da análise de processos em tramitação na segunda instância dos Juizados Especiais Federais no Ceará em novembro de 2012. Método: Foram coletados dados relacionados à composição dos polos da ação judicial, duração dos processos, valores das causas, posturas dos órgãos públicos e posicionamento do Poder Judiciário aos argumentos das partes. Resultados: Foram constatados o tratamento pulverizado outorgado aos reclamos dos usuários, de baixas complexidade e repercussão econômica; a demora na conclusão dos procedimentos derivada da postura dos órgãos de representação jurídica e a discreta taxa de prosperidade nos argumentos por eles manejados, além do ônus causado à União, mantenedora de todos os órgãos que atuam no sistema de justiça. Conclusões: Necessidade de expansão do modelo já praticado no âmbito do Comitê Interinstitucional de Resolução Administrativa de Demandas da Saúde (CIRADS), seja para se alcançar um término mais expedito das demandas ou diagnosticar as necessidades de ajustes no funcionamento do Sistema Único de Saúde (SUS).

Palavras-chave: Resolução alternativa de disputas; judicialização; demandas judiciais de saúde; Sistema Único de Saúde.

Resumen: Objetivo: Evaluar la factibilidad de implementar un mecanismo alternativo de solución de controversias en materia de salud, a través del análisis de casos pendientes ante la apelación de Juzgados Especiales Federales de Ceará, en el mes de noviembre de 2012. Método: Se recogieron datos relacionados con la composición de los polos de las demandas, la duración de los procesos, valores de las causas, actitudes de los organismos públicos y posicionamiento de la Magistratura a los argumentos de las partes. Resultados: Se ha observado el tratamiento pulverizado concedido a las demandas de baja complejidad y repercusión económica de los usuarios; el retraso en la finalización de los procedimientos, derivado de la 
postura de los órganos de representación jurídica y la discreta tasa de prosperidad de los argumentos manejados por ellos, además del encargo resultante para la Unión, mantenedora de todos los organismos que actúan en el sistema de justicia. Conclusiones: Necesidad de ampliar el modelo practicado en el ámbito del Comité Interinstitucional de Resolución Administrativa de Demandas de la Salud (CIRADS), sea para lograr una terminación más rápida de las demanda, sea para diagnosticar las necesidades de ajustes en el funcionamiento del Sistema Único de Salud (SUS).

Palabras clave: Resolución alternativa de conflictos; judicialización; pleitos judiciales de salud; Sistema Único de Salud.

Abstact: Objective: To discuss the viability of alternative dispute resolution (ADR) methods in health claims through analysis of lawsuits in Ceará Minor District Courts in November, 2012. Method: Data collecting was related to litigants' names, duration of proceedings, values of matter in controversy, posture of public administration and positioning of the Judiciary to the arguments. Results: Findings point to disorganized treatment to users' complaints of reduced complexity and economic repercussion; delay in claims conclusion due to the defendants' conduct and discrete success rate of their arguments, as well as the impact caused to the Union, which sustains the justice system. Conclusion: expansion of the ADR model, already practiced within the Alternative Health Dispute Resolution Interinstitutional Committee, is needed to achieve faster closure as well as to diagnose adjustment needs in the Unified Health System operation.

Keywords: Alternative dispute resolution (ADR); judicialization; health claims; public health system (Brazil).

\section{Introdução}

O fenômeno denominado "judicialização da saúde" teve como gênese ações que buscavam dispensação de fármacos antirretrovirais para tratamento da Síndrome da Imunodeficiência Adquirida (HIV/aids). Anteriormente, às súplicas não era conferido provimento pelo Judiciário sob o argumento de que os arts. 196 e ss. da Constituição Federal de 1988 tinha caráter meramente programático (Machado e Dain, 2012).

Todavia, a jurisprudência começou a evoluir no sentido da ofertar concretude às disposições constitucionais sobre o direito à saúde, tendo havido consolidação deste entendimento com a apreciação pelo Supremo Tribunal Federal do Recurso Extraordinário no 271.286, da Relatoria do Ministro Celso de Mello (Brasil, 2000), tendo sido consignado no bojo do voto condutor a impossibilidade de se aguardar indefinidamente a especificação normativa, em nível infraconstitucional, do projeto designado pelo art. 196 da Lex Legum (Brasil, 1988). 
A prestação de ações e serviços na área da saúde pública cada vez mais se concretiza por intermédio do Poder Judiciário. De uma postura tímida, Tribunais principiaram a chancelar pedidos de fornecimentos das mais variadas drogas e realização de procedimentos, tendo sido emblemático o caso em que foi assegurado a um grupo de pessoas tratamento em Cuba, apesar da ausência de protocolos autorizadores e a controvérsia sobre sua eficácia terapêutica (Brasil, 2011).

O Conselho Nacional de Justiça divulgou mapeamento sobre ações judiciais na área de saúde - excluídos os Tribunais de Justiça do Amazonas e de Pernambuco -, o qual revelou haver mais de 240 mil demandas pertinentes a esta temática atualmente em curso, sendo a imensa maioria alusiva a pleitos contra entes públicos e que visam acesso a medicamentos ou procedimentos pelo Sistema Único de Saúde - SUS (Brasil, 2011).

Consequentemente, os desembolsos efetuados por União, Estados e Municípios por conta de ordens judiciais em processos na área de saúde têm sofrido galopante progressão ao longo dos recentes anos. Estudo realizado pela AdvocaciaGeral da União (AGU), órgão incumbido de seu assessoramento jurídico, mostrou que, por força de decisões judiciais, os gastos diretos com aquisição de medicamentos, equipamentos e insumos evoluíram de $R \$ 2.441 .041,95$ em 2005 para $\mathrm{R} \$ 287.844 .986,16$ no ano de 2012 , ao mesmo tempo em que o montante de depósitos em juízos ou repasse aos demais entes federados foi incrementado de $\mathrm{R} \$$ 116.504,54 até $R \$ 60.885 .288,78$ (Brasil, 2012).

À vista deste panorama, sobressai inquietação acerca das causas para tamanha falta de êxito na defesa do Sistema Único de Saúde em Juízo e como remediá-lo. Haveria insuficiência do sistema para satisfazer as necessidades da população, deferimentos a técnicos, do ponto de vista sanitário, pelos Juízes ou até um caráter mercadológico, fomentado por laboratórios que visam induzir incorporação tecnológica de insumos no SUS (Machado e Dain, 2012).

Extreme de dúvidas é que legar solução dos problemas de assistência à saúde para o sistema jurídico não representa a via mais adequada. Tal opinião não deriva de preconceito sobre eventual desconhecimento por operadores do Direito sobre a realidade sanitária, mais em virtude da postura corriqueira adotada pelo Poder Público de preocupação imediatista em face dos reclamos processuais, evitando ao máximo um desfecho negativo ao invés de encarar as demandas como indicadores de falhas no atendimento e internalizá-las em seu planejamento. Diga-se também que 
a litigância individual não se coaduna às justificativas de sindicabilidade judicial na execução dos programas voltados à saúde pública, não havendo como se vislumbrar escassez de recursos para fornecimento de remédios que perfazem poucos milhares de reais (Amaral, 2010).

A vulnerabilidade do SUS no âmbito jurídico poderia ser elidida com o resgate do protagonismo na alocação dos recursos dispendidos hodiernamente em obediência a comandos jurisdicionais, por mecanismos de resolução das demandas alternativos à adjudicação (substituição da vontade das partes por decisão do Poder Judiciário), o que pode ser alcançado dentro ou fora de um processo e até antes de sua gênese, com evitação dos desdobramentos de uma condenação em juízo (i.e. imputação de custas, honorários de sucumbência, multas e juros).

Existem argumentos refratários à composição amigável de disputas, calcados majoritariamente na indisponibilidade do interesse público, tese que não se sustenta, seja porque há interesses Estatais de cunho eminentemente patrimonial (Souza, 2012) ou em face da dicção dos arts. 10 parágrafo único da Lei oㅜ 10.259/01 e 8o da Lei o 12.153/09 (este, ainda que com certa limitação), quanto aos Juizados Especiais Federais e da Fazenda Pública nos Estados e no Distrito Federal, respectivamente, bem como, no que pertine ao Código de Processo Civil, do art. 277 (procedimento sumário) e da alteração provocada em seu art. 331 pela Lei o 10.444/02, tornando necessário aprazamento de sessão conciliatória caso não ocorra julgamento antecipado da lide e o direito admita transação (locução que substituiu a pretérita "direito disponível").

Estudos, tal como o realizado por Cruz e Alves (2012), atestam as vantagens no funcionamento de instância administrativa voltada para análise e solução de conflitos com os usuários, evitando-se a via judicial, com redução de gastos oriundos de condenações ao menos proporcional ao incremento de ônus resultantes da satisfação espontânea de demanda da coletividade, isso sem considerar a melhoria na imagem institucional (accountability) do SUS como um todo, além da aproximação do ideal principiológico de eficiência insculpido na cabeça do art. 37 da Carta Magna.

O presente trabalho possui como escopo analisar a viabilidade econômica na implantação de métodos de resolução alternativa das controvérsias em saúde, no âmbito da Seção Judiciária do Ceará. 


\section{Metodologia}

Visando aferir parâmetros que subsidiem ou contrariem a hipótese levantada, procedeu-se à pesquisa quali-quantitativa nos feitos em tramitação nas duas Turmas Recursais da Seção Judiciária do Ceará no mês de Novembro de 2012.

A título de esclarecimento, as Turmas Recursais são órgãos do subsistema dos Juizados Especiais, previstos no art. 41, §1º da Lei no 9.099/95 e 21 da Lei o 10.259/01 e que, apesar de compostas por Juízes de primeiro grau, desempenham mutatis mutandis função jurisdicional equivalente à dos Tribunais Regionais Federais.

Optou-se pela coleta de dados em tais ações pelas seguintes causas: necessidade de delimitação espacial do universo de estudo; a Justiça Federal é o palco processual de atuação do Ministério Público da União, mirando-se em retorno teórico para a instituição promotora do curso ao qual esse artigo se dirige; a esmagadora maioria das demandas na área de saúde não possui valor da causa apurado conforme os ditames do art. 259 do CPC - que ultrapasse a alçada de competência dos Juizados Especiais Federais, qual seja, 60 salários mínimos, correspondentes a $R \$ 37.320,00$ na época da pesquisa; a observação na segunda instância (Turmas Recursais) permite identificar como vem se desenvolvendo a atuação dos órgãos de defesa do Poder Público, bem como mensurar o grau de êxito das alegações esgrimidas em favor do SUS.

O acesso aos processos foi oportunizado após contato formal com os Secretários de ambas as Turmas Recursais, devida autorização dos mesmos e solicitação de rol continente da numeração de todos os processos que envolvessem questões de saúde ajuizadas contra entes públicos da Administração Direta (União, Estado ou Municípios) ou Indireta (p. e., hospitais universitários), buscando acesso a medicamentos, insumos diversos (órteses e próteses, alimentos nutracêuticos) e procedimentos diversos (exames ou cirurgias) ao término do mês de novembro de 2012. As listagens entregues revelaram haver 10 processos em curso na $1^{a}$ Turma Recursal e 30 processos na $2^{\mathrm{a}}$ Turma Recursal.

A consulta aos processos deu-se por meio da geração ao pesquisador de nome de usuário (log-in) e senha pessoal para ingresso no Sistema CRETA (denominação do sistema processual eletrônico dos Juizados Especiais Federais da

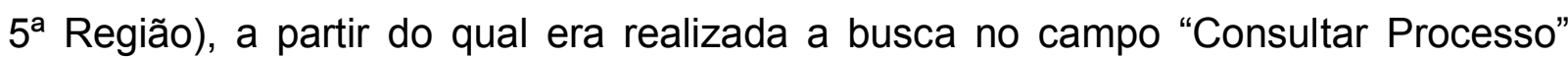
pelos números constantes das supracitadas listas. 
O acesso aos processos, que não ocasionou qualquer suspensão no andamento das demandas, ocorreu de maneira integral. Não havia ação sob segredo de justiça, sendo possível visualizar todas as informações de autuação e registro (i.e., nomes das partes e advogados, época do ajuizamento), movimentações e peças dos autos virtuais (petições, documentos, decisões, sentenças). Mesmo assim, por razões éticas, foram preservados dados pessoais e clínicos dos autores.

Da leitura da integralidade dos álbuns eletrônicos, foram pesquisadas as seguintes variáveis, consoante formulário padrão ministrado a cada processo: a) número do processo; b) número de integrantes do pólo ativo; c) data de ajuizamento, a partir da qual foi calculado o tempo de tramitação em meses até novembro de 2012, com arredondamento para um mês de períodos iguais ou superiores a 15 (dias) e desprezo dos que fossem inferiores a este marco; d) valor da causa (apurou-se o esboçado pela parte autora, salvo decisão judicial contrária); e) tipo da prestação (medicamento, insumo ou procedimento); f) patrocínio da causa pela Defensoria Pública da União (DPU) e/ou rogo por justiça gratuita; g) ocupantes do pólo passivo da lide (União, Estado do Ceará e/ou Município); h) deferimento de medida de urgência (art. 4ํ da Lei $n^{\circ}$ 10.259/01); i) caso deferida, cumprimento desta medida de urgência; j) argumentos de defesa levantados.

Com base em atuação prévia em Juizado Especial Federal, foram previamente selecionados, sem prejuízo de cômputo de outros: falta de comprovação de hipossuficiência econômica para ser atendida pela DPU, falta de comprovação de negativa da prestação solicitada; busca de tratamento privilegiado em face dos demais usuários do SUS; "reserva do possível" (impossibilidade de maior destinação de recursos orçamentários); não intromissão judicial em políticas públicas; ilegitimidade passiva; ilegitimidade passiva cruzada (quando alegada simultaneamente por mais de um réu); ausência de falhas no cumprimento das atribuições legais; bis in idem à União (duplicidade na obrigação de custeio); óbices legais impostos pela Constituição Federal e/ou Lei de Responsabilidade Fiscal; pedido genérico; inexistência de obrigação em fornecer especificamente a prestação requestada (i.e., quando há medicamento similar dispensado pelo SUS); incompetência da Justiça Federal (normalmente em conjunto com a alegação de ilegitimidade da União, redundância por força do art. 109 da CF/88); k) espécie do julgamento em primeira instância (favorável ou desfavorável ao autor; sentença de procedência, improcedência ou sem resolução do mérito); I) fundamento da sentença, 
caso esta tenha sido desfavorável ao autor; $\mathrm{m}$ ) recurso apresentado por integrante do pólo passivo; n) tipo do recurso (intermediário - contra decisão de urgência - ou inominado - contra sentença definitiva); o) existência de acórdão da Turma Recursal.

Efetuou-se ulterior consolidação das informações obtidas em planilhas com o auxílio do programa Microsoft Excel, posteriormente convertidas em tabelas, que serviram de guia para o debate dos resultados.

\section{Resultados e discussão}

Inicialmente, pontua-se que as 40 ações detinham somente um componente em seu pólo ativo, constituindo todas reclamações individuais, o que reforça ainda mais o caráter atomizado com que vêm sendo enfrentadas as demandas de saúde e que impossibilita a visão global do Magistrado sobre a integralidade do SUS, bem como das potenciais externalidades negativas de uma decisão judicial, qualquer seja seu conteúdo. Assim, a defesa jurídica, capitaneada pela Advocacia-Geral da União ou Procuradorias Estaduais e Municipais, sempre queda assoberbada, tendendo a elaborar contestações padronizadas, às vezes dotadas de trechos impertinentes com o objeto da ação e em imensa maioria desguarnecidas do cabedal técnico específico da saúde pública, produzindo, assim, pouco impacto na formação do convencimento do Juiz.

Sobressaiu da observação dos autos a reduzida (e inesperada) frequência com que os Municípios apresentavam peças de defesa, apesar de expressamente intimados para tanto, deixando para se manifestar na eventualidade de decisão contrária a seus interesses. O motivo para esse fenômeno talvez advenha de impressão das Municipalidades sobre a maior força orçamentária do Estado e da União, sendo esses, na ordem disposta, os que mais laboram em prol de suas pretensões.

Desde já se indica que todos os processos aguardavam julgamento pelas Turmas Recursais.

Quanto à duração dos processos, 85\% vêm desenrolando por lapso igual ou maior que 12 meses, sendo que o tempo médio de tramitação corresponde a 24,4 meses. A ação mais nova tem 5 meses, ao passo que a mais antiga, 56 meses. 
Tabela 1. Processos na área de saúde de competência das Turmas Recursais da Seção Judiciária do Ceará, segundo a duração, no mês de novembro de 2012

\begin{tabular}{lrc}
\hline Tempo de tramitação em meses & № & $\%$ \\
\hline$<6$ & 1 & 2,5 \\
\hline $6 \mathrm{a}<12$ & 5 & 12,5 \\
\hline $12 \mathrm{a}<24$ & 19 & 47,5 \\
\hline $24 \mathrm{e}+$ & 15 & 37,5 \\
\hline Total & 40 & 100,0 \\
\hline
\end{tabular}

Fonte: Juizados Especiais Federais da $5^{\mathrm{a}}$ Região. Resultado da pesquisa elaborada pelo Autor.

À primeira vista, a média de duração processual não se afigura tão prolongada. Todavia, deve-se levar em conta que, segundo o Relatório "Justiça em Números 2012" (Brasil, 2012), os Juizados Especiais Federais da 5ª Região possuem a menor taxa de congestionamento processual $(60,4 \%)$ de todas as Regiões da Justiça Federal (o percentual total é de $70,6 \%$ ), ao passo que as Turmas Recursais da mesma Região têm desempenho pior (68,1\%) que o geral (65,5\%), mesmo paralelo observado na Turma Regional de Uniformização (65,2\% de congestionamento para a $5^{\text {a }}$ Região, possuindo toda a Justiça Federal índice de 58,7\%).

O que se conclui, portanto, é que no primeiro grau os processos avançam mais rapidamente que nas demais instâncias. A possibilidade dilatória por uma série de recursos ou incidentes previstos em lei - seja para o mesmo órgão jurisdicional ou Turmas Regional ou Nacional de Uniformização, Superior Tribunal de Justiça ou Supremo Tribunal Federal - torna impossível prever o instante de desfecho final de qualquer das ações e, por conseguinte, da eventual fruição do direito postulado.

Em relação à repercussão econômica das ações, o valor médio da causa indicado pelos autores (não houve qualquer impugnação da parte contrária, tampouco retificação judicial ex officio) constitui $R \$ 10.091,06$. O valor máximo foi de $R$ \$ $37.320,00$, o qual, à época, representava o teto quantitativo da alçada de competência dos Juizados Especiais Federais (60 salários mínimos), não havendo na petição inicial elementos a partir dos quais fosse possível aquilatar a correção desta estimativa. Por sua vez, $\mathrm{R} \$ 50,00$ representou o menor valor da causa, curiosamente em um dos processos com tramitação mais alongada (55 meses). 
Tabela 2. Processos da área de saúde de competência das Turmas Recursais da Seção Judiciária do Ceará, segundo o valor da causa (em $R \$$ ), no mês de novembro de 2012.

\begin{tabular}{lrc}
\hline \multicolumn{1}{c}{ Valor da causa (R\$) } & № & $\%$ \\
\hline$<1.000,00$ & 7 & 17,5 \\
\hline $1.000,00 \mathrm{a}<5.000,00$ & 8 & 20,0 \\
\hline $5.000,00 \mathrm{a}<10.000,00$ & 10 & 25,0 \\
\hline $10.000,00 \mathrm{a}<20.000,00$ & 8 & 20,0 \\
\hline $20.000,00 \mathrm{e}+$ & 7 & 17,5 \\
\hline Total & 40 & 100,0 \\
\hline
\end{tabular}

Fonte: Juizados Especiais Federais da $5^{\mathrm{a}}$ Região. Resultado da pesquisa elaborada pelo Autor.

Quase dois terços do universo dos processos pesquisados (62,5\%) detinham valor da causa inferior a dez mil reais, o que leva a crer pela concentração dos pedidos em patamares relativamente baixos, comparados aos padrões atuais de custeio dos tratamentos de saúde.

A maioria dos pedidos encaminhados ao Judiciário $(72,5 \%)$ concernia à dispensação de medicamentos, seguidos pela realização de procedimentos $(17,5 \%)$ e, por último, à entrega de insumos (10\%). Tamanha presença de um objeto determinado tende a noticiar carência específica do SUS quanto à baixa estimativa de demanda, distribuição ou estoque dos fármacos.

Tabela 3. Processos da área de saúde de competência das Turmas Recursais da Seção Judiciária do Ceará, segundo o objeto do pedido, no mês de novembro de 2012.

\begin{tabular}{lrc}
\hline \multicolumn{1}{c}{ Tipo de prestação } & No & $\%$ \\
\hline Medicamentos & 28 & 70,0 \\
\hline Procedimentos (exames, cirurgias) & 7 & 17,5 \\
\hline Outros Insumos (ex. órteses, próteses) & 5 & 12,5 \\
\hline Total & 40 & 100,0 \\
\hline
\end{tabular}

Fonte: Juizados Especiais Federais da $5^{\mathrm{a}}$ Região. Resultado da pesquisa elaborada pelo Autor.

Algumas peculiaridades verificadas nos pedidos endereçados: apenas em uma petição inicial o medicamento foi qualificado como não integrante da Lista SUS (o que não condiz com os resultados dos julgamentos, onde sete sentenças indeferiram os pedidos com lastro na existência de fármacos similares dispensados pelo Sistema, como se verá adiante); dentre os procedimentos, três diziam respeito a exames, dois à colocação de stents farmacológicos e dois eram referentes a outros procedimentos cirúrgicos; na seara dos insumos, havia pedidos singulares de oferta de medicamento 
nutracêutico, entrega de cadeira de rodas motorizada e andador, bem como dois pedidos de fornecimento de aparelho de pressão positiva contínua nas vias aéreas (CPAP) em função de apnéia do sono.

A Defensoria Pública da União foi responsável pelo ajuizamento de $85 \%$ das causas (34 processos), tendo sido as restantes (6) patrocinadas por advogados privados, ainda que com protestos pelos auspícios de gratuidade de justiça dispostos na Lei $n^{0}$ 1.060/50 (Brasil, 1950).

Haja vista que o art. 1ำ da Resolução no 13 de 25 de outubro de 2006, do Conselho Superior da Defensoria Pública da União (Brasil, 2006), presume como necessitado de seus serviços integrante de família cuja renda mensal não exceda o limite de isenção do Imposto de Renda e como não havia qualquer declinação de ganhos por qualquer dos autores, torna-se possível afirmar que ao menos $85 \%$ dos usuários que acionaram o Judiciário inseriam-se em nível de renda familiar mensal inferior a $\mathrm{R} \$ 1.637,11$ - cf. Tabela Progressiva Mensal da Lei ํㅡ 11.482/2007 vigente à época da pesquisa -, ao passo que os demais, ainda que possuidores de renda superior, declararam-se impossibilitados de prover às despesas do processo, nos termos dos arts. $2^{\circ}$, parágrafo único e $4^{\circ}$ da Lei $n^{\circ}$ 1.060/50.

Considerando que, nas ações pertinentes a obrigação por prazo indeterminado, como é a dispensação de um medicamento para enfermidade crônica, o quantum do pedido deverá abranger, no mínimo, uma prestação anual - 12 meses, cf. art. 260 do Código de Processo Civil (CPC) (Brasil, 1973) -, obtém-se como resultado de fracionamento mensal do valor médio da causa $(R \$ 10.091,06)$ a importância de $R \$$ 840,92 , que certamente redunda em significativo impacto em orçamento de $R \$ 1.637,11$, perfil de hipossuficiênca no qual se enquadram a maioria dos autores, assistidos pela Defensoria Pública da União e, sem dúvida, carentes de atendimento pelo SUS.

O polo passivo das demandas sempre contava com a União, em $82,5 \%$ das vezes o Estado (no caso, do Ceará) era cumulativamente demandado, enquanto o Município de residência do autor foi qualificado como réu em 31 processos ( $77,5 \%$ do total).

Tabela 4. Processos da área de saúde de competência das Turmas Recursais da Seção Judiciária do Ceará, segundo o pólo passivo, no mês de novembro de 2012

\begin{tabular}{lcc}
\hline \multicolumn{1}{c}{ Presença no Polo Passivo } & No & $\%$ \\
\hline União & 40 & 100,0 \\
\hline Estado & 33 & 82,5 \\
\hline Município & 31 & 77,5 \\
\hline
\end{tabular}

Fonte: Juizados Especiais Federais da 5 ${ }^{\mathrm{a}}$ Região. Resultado da pesquisa elaborada pelo Autor. 
O manejo de causa em face da União é fato principiador da competência da Justiça Federal, nos termos do art. 109 da Constituição Federal (Brasil, 1988), bastando esta alegação para ser franqueado o protocolo da ação. Todavia, incidirá subsequente controle judicial sobre a adequação da presença da União no processo através da verificação de sua legitimidade passiva, o que pode redundar em sentenças não favoráveis ao autor, mesmo que não decidam o mérito do litígio, como se verá mais adiante. E este será o ponto nodal sobre a viabilidade/necessidade de implementação de um meio alternativo de resolução de controvérsias na área da saúde.

Apesar de veicularem pleitos relacionados ao direito de atenção à saúde, dotado de status constitucional (arts. 60 e 196 e ss. da CF/88), somente $35 \%$ das ações (14 processos) tiveram medidas de urgência deferidas no limiar dos processos, o que denota cautela dos Magistrados na condenação do Poder Público e contrasta com achados em outras pesquisas (Ventura et al., 2012 e Marques; Melo; Santos, 2011), ao passo que houve notícia de cumprimento da ordem judicial em 12 feitos (30\% do total de processos), havendo nítido esforço dos entes políticos (mormente a União) em atender aos comandos do Judiciário.

No que se relaciona às teses de defesa em favor do SUS, notou-se que as contestações veiculavam argumentos jurídicos reprisados de forma padronizada, em grande parte desacompanhados de alegações técnico-sanitárias (manifestadas em apenas $12,5 \%$ dos processos) e, em menor grau, dissociadas do objeto da causa.

As alegações mais frequentes foram sustentadas pela União: ilegitimidade passiva e imputação dúplice de custeio ( $87,5 \%$ e $65 \%$ das vezes, respectivamente). A ilegitimidade passiva da União guarda sintonia com o argumento de incompetência da Justiça Federal (35\%), visto que este deriva daquela. Por sua banda, o bis in idem é paráfrase da objeção de ausência de falha nas atribuições do ente político $(27,5 \%)$. Vê-se, portanto, que considerável quota da defesa da União concentra-se, em suma, num único aspecto: impossibilidade de ser demandado, pois está cumprindo suas obrigações legais. 
Tabela 5. Processos da área de saúde de competência das Turmas Recursais da Seção Judiciária do Ceará, segundo o argumento da defesa nas contestações, no mês de novembro de 2012

\begin{tabular}{|c|c|c|}
\hline Argumento de Defesa & № & $\%$ \\
\hline llegitimidade passiva & 35 & 87,5 \\
\hline $\begin{array}{l}\text { Bis in idem para a União (ação judicial criará } \\
\text { duplicidade de despesa) }\end{array}$ & 26 & 65,0 \\
\hline Reserva do possível & 26 & 65,0 \\
\hline $\begin{array}{l}\text { Insindicabilidade jurisdicional (invasão de atribuições } \\
\text { do Poder Executivo) }\end{array}$ & 24 & 60,0 \\
\hline Não obrigação de fornecer prestação específica & 22 & 55,0 \\
\hline $\begin{array}{l}\text { llegitimidade passiva cruzada (mais de um ente } \\
\text { político alega não poder ser demandado judicialmente) }\end{array}$ & 22 & 55,0 \\
\hline $\begin{array}{l}\text { Busca de tratamento privilegiado (quebra da isonomia } \\
\text { frente a usuários do SUS que não acionam Judiciário) }\end{array}$ & 17 & 42,5 \\
\hline Incompetência da Justiça Federal & 14 & 35,0 \\
\hline $\begin{array}{l}\text { Não comprova que a prestação solicitada tenha sido } \\
\text { indeferida }\end{array}$ & 13 & 32,5 \\
\hline Ausência de falha nas atribuições do ente político & 11 & 27,5 \\
\hline $\begin{array}{l}\text { Óbices orçamentários por conta da Constituição } \\
\text { Federal ou da Lei de Responsabilidade Fiscal }\end{array}$ & 9 & 22,5 \\
\hline $\begin{array}{l}\text { Falta de interesse de agir (não acionou SUS } \\
\text { previamente) }\end{array}$ & 8 & 20,0 \\
\hline $\begin{array}{l}\text { Não comprova hipossuficiência econômica para ser } \\
\text { assistido pela Defensoria Pública da União }\end{array}$ & 4 & 10,0 \\
\hline Pedido genérico & 3 & 7,5 \\
\hline SUS fornece medicamento & 1 & 2,5 \\
\hline Uso off-label (indicação sem registro na Anvisa) & 1 & 2,5 \\
\hline Necessidade de prova pericial & 1 & 2,5 \\
\hline Necessidade de internação voluntária do paciente & 1 & 2,5 \\
\hline Medicamento com registro suspenso na Anvisa & 1 & 2,5 \\
\hline
\end{tabular}

Fonte: Juizados Especiais Federais da 5ํㅡ Região. Resultado da pesquisa elaborada pelo Autor.

Notável que em $55 \%$ das causas mais de um ente político agitou em seu favor a preliminar de ilegitimidade passiva cruzada, o que pode representar desconhecimento da repartição de competência do SUS estabelecida na Lei no 8.080/90 (Brasil, 1990), até porque a execução de ações e serviços de saúde cabe a Estados e Municípios, de modo prioritário ao último (art. 18, I) e supletivamente àquele (art. 17, III), mas nunca à União, cujas funções executivas restringem-se a vigilância epidemiológica e sanitária de portos, aeroportos e fronteiras e sobre a política nacional e produção de insumos e equipamentos para a saúde (art. 16, VI , VII e X). 
Os resultados dos julgamentos em primeiro grau de jurisdição foram curiosa e rigorosamente divididos: de um total de 40 ações pesquisadas, em 20 houve pronunciamento favorável ao pedido do autor e nas demais 20 , sentenças ou decisões que não concederam a pretensão, ainda que não tenham resolvido o mérito.

Tabela 6. Processos da área de saúde de competência das Turmas Recursais da Seção Judiciária do Ceará, segundo o Ato do Juiz (cf. arts. 162, 267 e 269 do Código de Processo Civil) de primeiro grau, no mês de novembro de 2012

\begin{tabular}{lrr}
\multicolumn{1}{c}{ Julgamento } & № & $\%$ \\
\hline Sentença de acolhimento do pedido & 20 & 50 \\
\hline Sentença de rejeição do pedido & 14 & 35 \\
\hline Sentença de extinção sem resolução do mérito & 4 & 10 \\
\hline $\begin{array}{l}\text { Decisão declinatória de competência (com remessa à } \\
\text { Justiça Estadual) }\end{array}$ & 2 & 5 \\
\hline Total & 40 & 100 \\
\hline
\end{tabular}

Fonte: Juizados Especiais Federais da 5 ${ }^{\underline{a}}$ Região. Resultado da pesquisa elaborada pelo Autor.

Tal constatação diverge do que apontam certos estudos realizados em outras partes do Brasil (Ventura et al., 2012; Marques e Dallari, 2007), de que o Judiciário estaria majoritariamente reconhecendo o direito dos Autores à assistência pelo SUS.

Os fundamentos das decisões que não acolheram o pedido concentram-se em 3 grupos: impossibilidade da União ser compelida a realizar o objeto da ação - o que, em última análise, corresponde ao reconhecimento de sua ilegitimidade passiva, ainda que por via transversa; dispensação de fármaco eficaz pelo SUS; outras questões técnicas, como possibilidade de reação adversa fatal do medicamento solicitado.

Demais temas jurídicos, como reserva do possível, não intromissão do Judiciário na saúde, busca de tratamento privilegiado e limitações orçamentárias não sensibilizam os Julgadores, sobretudo por conta da escolha institucional da Advocacia-Geral da União em manejar a tutela jurídica do SUS como repulsa a processos individuais, sem articulação de mecanismo preventivo de demandas (há exceções, adiante nominadas).

Uma análise perfunctória dos dados acima pode levar à crença de que a defesa judicial do SUS vem auferindo considerável êxito, prosperando em metade dos casos. Porém, há aspectos que repelem a veracidade desta extrapolação, além do suprarreferido incremento de gastos resultantes de ações judiciais. 
Tabela 7. Processos da área de saúde de competência das Turmas Recursais da Seção Judiciária do Ceará, segundo o fundamento dos julgados desfavoráveis ao usuário/autor, no mês de novembro de 2012

\begin{tabular}{|c|c|c|c|}
\hline $\begin{array}{c}\text { Fundamento dos julgados desfavoráveis ao } \\
\text { usuário/autor }\end{array}$ & № & $\%$ & $\begin{array}{l}\text { Agrupamento } \\
\text { das razões }\end{array}$ \\
\hline $\begin{array}{l}\text { União não pode ser obrigada a fornecer } \\
\text { insumo (órtese) }\end{array}$ & 1 & 2,5 & \multirow{3}{*}{$\begin{array}{l}\text { Impossibilidade } \\
\text { de a União ser } \\
\text { demandada } \\
\text { (Ilegitimidade) }\end{array}$} \\
\hline $\begin{array}{l}\text { União não pode ser obrigada a fornecer } \\
\text { medicamento }\end{array}$ & 1 & 2,5 & \\
\hline $\begin{array}{l}\text { llegitimidade passiva da União (seja por } \\
\text { sentença ou decisão) }\end{array}$ & 6 & 15,0 & \\
\hline Fármaco similar dispensado pelo SUS & 7 & 17,5 & \multirow{2}{*}{$\begin{array}{l}\text { Existência de } \\
\text { medicamento } \\
\text { SUS eficaz }\end{array}$} \\
\hline $\begin{array}{l}\text { Falta de comprovação sobre insuficiência dos } \\
\text { fármacos da Lista SUS }\end{array}$ & 1 & 2,5 & \\
\hline Ausência de pedido ao SUS & 1 & 2,5 & \multirow{4}{*}{$\begin{array}{l}\text { Outras } \\
\text { questões } \\
\text { técnicas }\end{array}$} \\
\hline Exame solicitado não era imprescindível & 1 & 2,5 & \\
\hline $\begin{array}{l}\text { Não evidenciou indispensabilidade do insumo } \\
\text { (respirador) }\end{array}$ & 1 & 2,5 & \\
\hline $\begin{array}{l}\text { Fármaco solicitado apresenta risco para faixa } \\
\text { etária do usuário }\end{array}$ & 1 & 2,5 & \\
\hline
\end{tabular}

Fonte: Juizados Especiais Federais da $5^{\mathrm{a}}$ Região. Resultado da pesquisa elaborada pelo Autor.

Dos 20 feitos onde deixou de ser agasalhada a pretensão autoral, em oito - ou seja, $40 \%$ dos pronunciamentos favoráveis ao SUS - foi determinante o entendimento pela ausência de vínculo legal mantenedor da União na qualidade de ré (ilegitimidade ad causam), existente o mesmo apenas quanto ao Estado e/ou Município.

A ótica dos Magistrados que assim decidiram percebe a conjugação de esforços tratada na Constituição Federal relacionada ao financiamento, com garantia da aplicação mínima de recursos (arts. 196 e 198, $\$ \S 1^{\circ}$ e $2^{\circ}$ ), sendo, quanto ao atendimento, disciplinado pela cabeça do art. 198 da CF/88 que o mesmo se dará em uma rede regionalizada e hierarquizada, não sendo encargo da União oferecer diretamente todo serviço à população, justamente porque Estados e Municípios são destinatários de inversões para este objetivo, compreensão roborada pelo art. $7^{\circ} \mathrm{da}$ Lei no 8.080/90, determinante que ações e serviços do SUS são desempenhados pelos princípios de conjugação dos recursos financeiros, tecnológicos, materiais e humanos, mas com organização dos serviços de modo a evitar duplicidade de meios para fins idênticos (incisos XI e XIII). Assim, praticando a União os devidos repasses orçamentários (arts. 34 e 35 da Lei no 8.080/90), inexistiria vínculo jurídico que a ligasse a falha na prestação do serviço ou ação de saúde a usuário do SUS. 
Entretanto, a linha de interpretação do Supremo Tribunal Federal segue outro diapasão, albergando possibilidade de indistinto acionamento de qualquer dos entes políticos, os quais estariam ligados por responsabilidade solidária advinda da especialmente da competência comum estabelecida pelo inciso II do art. 23 da Constituição Federal. A reprise de julgados no mesmo viés inclusive estimulou apresentação pelo Defensor Público-Geral da União da Proposta de Súmula Vinculante (PSV) o 4, capaz de abalar irreversivelmente a matriz organizacional do SUS, já que visa o reconhecimento definitivo da responsabilidade solidária de União, Estados e Municípios e categórica repulsa da alegação de ilegitimidade passiva, além de expressa chancela ao bloqueio de orçamento de qualquer destas pessoas jurídicas de direito público, a qualquer tempo, para custeio de fármacos ou tratamentos médicos. O julgamento da PSV 4 encontra-se temporariamente sobrestado, aguardando resolução do Recurso Extraordinário oㅡ 566.471 (STF, 2012). De toda sorte, apenas um câmbio radical na composição da mencionada Corte - o que não se afigura viável - poderia alterar a mantença da jurisprudência atual.

A incidência deste quadro sobre os resultados da pesquisa faz com que se desconsiderem os julgamentos anunciadores de ilegitimidade passiva da União, pelo grau de certeza sobre sua revisão em grau de recurso, fazendo com que se possa readequar o êxito da defesa do SUS.

Do ajuste de parâmetros que leva ao revés em $70 \%$ dos casos, exsurge pensamento sobre vantagens em implementar um sistema alternativo de resolução de conflitos na área de saúde, passível de elidir a via judicial, pois salta aos olhos a antieconomicidade no emprego da força laboral dos integrantes das organizações atuantes nos setores da relação processual (Defensoria Pública, AGU e o Poder Judiciário, isso quando não haja incapaz que demanda a intervenção do Ministério Público) em procedimentos que, além de não imprimir celeridade à resolução da problemática, especialmente pela rotineira demora causada pela miríade de opções recursais (de 14 processos onde houve deferimento de medida de urgência, foram interpostos recursos em 11 e dos 20 processos onde se apurou inicialmente julgamento desfavorável à União, esta manejou recurso inominado 19 vezes, o que ressalta 0 intento dilatório), têm desenlace majoritariamente desfavorável a quem sustenta o todo destas instituições, a saber, a União. 
Adira-se a isso que:

- a pesquisa denunciou a franca superioridade nos pedidos de medicamentos (em 70\% das ações), situação de mais desembaraçada resolução, seja por remanejamento de estoque da própria União (se for de sua alçada) ou gestão articulada junto a Estados e Municípios. Todavia, presencia-se falta de entendimento entre os níveis administrativos do SUS, a ponto de ter sido identificada Ação Civil Pública nº 0005798-63.2012.4.05.8400 da União contra o Estado do Rio Grande do Norte, visando compelir à regularidade de dispensação nos postos estaduais de atendimento ambulatorial;

- à míngua de elementos, a pesquisa não pôde distinguir se a DPU (patrocinadora de $85 \%$ das causas pesquisadas), após o reclame do usuário do SUS, solicita informações dos entes públicos e/ou busca a solução amigável da controvérsia, dando a entender que são, ao menos, reduzidas as iniciativas de apuração prévia de eventuais responsabilidades, bem como há predileção pelo imediato ajuizamento das demandas;

- inexiste controle de acesso da população aos Juizados Especiais, o qual é gratuito e prescinde de assistência por profissional habilitado ou qualquer formalidade, bastando ao usuário, munido de escassa documentação, registrar seu pedido no respectivo Setor de Atendimento, facilidade que tende a converte estes órgãos do Poder Judiciário em verdadeiro "balcão de reclamações" da Administração Pública.

Deve-se buscar, portanto, o abandono de fórmulas exclusivamente jurídicas, com a implementação de métodos paraprocessuais complementares ao sistema instrumental, visando melhor oportunizar adequada e eficiente prestação de ações e serviços de saúde (Azevedo, 2012)

Esta concepção é respaldada pela análise econômica, cujo pragmatismo vem subsidiando, cada vez mais, a adoção de posturas jurídicas. No âmbito da Procuradoria-Geral da Fazenda Nacional (PGFN), a quem incumbe a cobrança de créditos da União, apurou-se que o custo médio de uma ação execução fiscal é de $R \$$ $5.606,67$, com probabilidade de recuperação integral do valor da ordem de $25,8 \%$, do que se conclui ser o breaking even point, piso economicamente justificável para ajuizamento do executivo fiscal, de $\mathrm{R} \$ 21.731,45$ (IPEA, 2011). Traduzindo: inauguração de processo judicial para reaver quantia inferior à sobredita representa prejuízo à União. 
Desenvolvendo raciocínio semelhante ao universo dos processos sobre demandas na área de saúde pesquisados e considerando que nestes a união ocupa a posição de ré, seria plausível litigar em processos cujo objeto tenha expressão acima de $R \$ 7.063,74$, derivado do valor médio das causas $(R \$ 10.091,06)$ e a taxa ajustada de insucesso das teses ventiladas como defesa (70\%).

Houvesse tal mecanismo de "filtro" extrajudicial das demandas em saúde e fossem a ele submetidos processos com valor inferior ao suso indicado, poderiam ter sido evitadas 19 das 40 ações pesquisadas.

Já existe no seio da Advocacia-Geral da União iniciativa similar à ora aventada, o Comitê Interinstitucional de Resolução Administrativa de Demandas da Saúde (CIRADS), composto por representantes da AGU, DPU, Procuradorias Estadual do RN e Municipal de Natal, bem como das respectivas Secretarias de Saúde, e que tem por objetivo solucionar administrativamente demandas ligadas ao SUS, ajuizadas ou não, que aportaram na Defensoria-Pública da União. No decorrer de 38 reuniões de análise de casos realizadas desde 2009, chega-se ao desfecho expedito de questões que certamente se alongariam por anos no Judiciário. À guisa de exemplo, na $3^{\text {a }}$ reunião do dito órgão foi analisado um caso sobre dispensação negada de PROLOPA em virtude da dosagem receitada não se adequar à do medicamento ofertado pelo SUS e solucionado unicamente com a expedição de ofício ao médico prescritor para adequar a posologia do fármaco (Brasil, 2012).

A repercussão do CIRADS foi tão positiva no Rio Grande do Norte que sua Defensoria Pública fomentou a criação do "SUS Mediado", que também visa reduzir a judicialização da saúde através do atendimento a demandas voltadas contra o Estado ou Prefeituras que firmem convênio com o programa, com alcance de picos de $60 \%$ de acordos imediatos (Rio Grande do Norte, 2012).

Poderia, assim, haver expansão do CIRADS à Seção Judiciária do Ceará e demais Unidades Federativas ou incorporação de suas atribuições pela Câmara de Conciliação e Arbitragem da Administração Federal (CCAF), cujo espectro de atuação vem continuamente sendo expandido desde sua gênese em 2007. No início, a CCAF era voltada apenas para entes federais, hoje respondendo por controvérsias que envolvam a Administração Pública Federal e suas congêneres Estaduais, Distrital e Municipais (Brasil, 2012), o que não deixa de abranger os conflitos envolvendo o SUS. 
Não obstante sua denominação ou local de funcionamento, o órgão especializado teria condições de monitorar, a partir dos casos enfrentados, os índices e perfis de indeferimentos administrativos, verificar se os mesmos estão conformes as diretrizes do SUS e atuar para a correção de práticas não albergadas pela legislação ou, no que for possível, formas de reparar a necessidade do Usuário previamente à busca pelo Judiciário.

\section{Conclusões}

Da tendência jurisprudencial sobre a concretização do direito constitucional à saúde redundou a escalada de processos contra solicitações não atendidas pelo SUS, fenômeno que produz avantajado impacto nas contas públicas.

Os prejuízos derivados da judicialização de controvérsias na área sanitária refletem mais gravemente na União, a qual não somente arca com repasses orçamentários a Estados, Distrito Federal e Municípios, mas também recebe determinações judiciais para financiar procedimentos e insumos em relação aos quais já teria desembolsado sua contrapartida.

Ademais, percebe-se que muitas vezes a solução mais adequada do ponto de vista integrativo de um sistema (i.e., remanejamento de estoque de um medicamento) não se afigura plausível de adoção dentro de um processo judicial, sobretudo diante da postura processual dos entes políticos, majoritariamente elisiva e de parca informação qualificada.

Hodiernamente não mais prevalecendo vozes contrárias à autocomposição de litígios pelo Estado, é de relevo notar que a transferência da resolução dos conflitos na área da saúde a um palco extraprocessual permite, ao invés de ser expedida simples negativa, equalizar, tanto quanto possível, condições do SUS com as necessidades dos usuários (p.ex., substituição do medicamento receitado por outro constante da listagem de dispensação ordinária ou marcação de consulta/procedimento em prazo razoável). Desta forma, além de se incrementar a prestação de essencial serviço público, elide-se todo um dispêndio com o aparato Judiciário e dos órgãos que em torno dele atuam e os desdobramentos oriundos de eventuais condenações.

Objetivando confirmação sobre vantagens do estabelecimento de mecanismo alternativo ao judicial para resolução de demandas na saúde, procedeu-se à pesquisa em ações com trâmite nas Turmas Recursais da Seção Judiciária do Ceará, por conta 
da incidência destas causas na alçada de competência dos Juizados Especiais Federais e do estágio procedimental avançado dos feitos. A coleta de dados focalizou principalmente informações sobre as partes e seu patrocínio, duração dos processos, repercussão econômica, postura dos órgãos de representação jurídica do Poder Público e posicionamento do Judiciário a pleitos de urgência (e seu cumprimento) e aos argumentos de defesa.

Resultados apanhados confirmam a hipótese levantada, evidenciando a necessidade de um tratamento articulado das demandas na saúde, ao invés de se encarar uma pulverização de requerimentos individuais de baixas complexidade (franca maioria sobre dispensação de medicamentos) e expressão monetária (média de $R \$ 10.091,06)$, sendo questionável a economicidade na resistência dos órgãos de representação jurídica, onerosa simultaneamente aos quadros do Judiciário, AGU e DPU (esta patrocinadora de $85 \%$ das causas), todos sustentados pelo orçamento da União, por tempo médio superior a 2 anos, quando a via extrajudicial poderia alcançar o desfecho em lapso mais reduzido.

Esta constatação ganha substância ao se acoplar com o discreto índice de sucesso das defesas judiciais (30\%), ajustado seguindo a jurisprudência dominante que prevalece nas instâncias superiores e muito provavelmente impulsionará o acatamento da Proposta de Súmula Vinculante o 4 para, desconsiderando a tripartição de competências estabelecida pela legislação ordinária e regulamentar, sacramentar a responsabilidade solidária de todos os entes políticos em questões de saúde, em resultado sendo a União atingida de forma mais gravosa.

Ministrando-se raciocínio similar ao empregado pelo IPEA na apuração do custo-benefício das execuções fiscais da dívida ativa da União, indica-se breaking point ( $\mathrm{R} \$ 7.063,74$ ) aquém do qual se torna antieconômica defesa em juízo, roborando o funcionamento de mecanismo alternativo de composição de disputas, sendo que no universo pesquisado uma "advocacia preventiva" lastreada no escalão citado poderia minorar o número de ajuizamentos quase à metade.

A Advocacia-Geral da União já possui iniciativa semelhante à aventada CIRADS, todavia restrita ao Rio Grande do Norte, a despeito dos resultados obtidos, sendo devida a expansão desta prática a outras unidades federativas, seja como um órgão autônomo ou fração de competência de outro já existente, como a Câmara de Conciliação e Arbitragem (CCAF), o que possibilitaria, inclusive, um mapear as carências do SUS, visando incorporação de novos procedimentos ou tecnologias, 
sempre buscando alcançar garantir as universalidade e integralidade no atendimento dos serviços e ações de saúde.

\section{Referências}

AMARAL, Gustavo. Direito, escassez e escolha. Critérios jurídicos para lidar com a escassez de recursos e as decisões trágicas. Rio de Janeiro: Lumen Juris, 2010. ISBN 978-85-3750-672-1.

AZEVEDO, André. O processo de negociação: uma breve apresentação de inovações epistemológicas em um meio autocompositivo. [on line] Disponível em: <http://gesan.ndsr.org/docmanualespecializacao15Processodenegociacao.pdf>. [s.d.]. Acesso em 15 nov. 2012.

BRASIL. ADVOCACIA GERAL DA UNIÃO. Intervenção judicial na Saúde Pública. [on line] Disponível em: <http://portalsaude.gov.br/portalsaude/arquivos/ pdf/2012/Ago2012/Panorama.pdf>. 2012. Acesso em 5 jan. 2013.

Gastos. [on line] Disponível em: <http://portalsaude.saude.gov.br/ portalsaude/arquivos/pdf/2012/Dez/17/EVOLUcaOGASTOS.pdf>. 2012. Acesso em 5 jan. 2013.

- Cartilha da Câmara de Conciliação e Arbitragem da Administração Federal (CCAF). [on line] Disponível em:<http://www.agu.gov.br/sistemas/site/TemplateTextoThumb.aspx?idConteudo=21 7576\&id_site=774>. 2012. Acesso em 4 dez. 2012.

Comitê Interinstitucional de Resolução Administrativa de Demandas da Saúde (CIRADS). [on line] Disponível em:<http://www.agu.gov.br/sistemas/site/TemplatelmagemTexto.aspx?idConteudo=9 7046\&id_site=1180>. 2012. Acesso em 12 dez. 2012.

BRASIL. CONSELHO NACIONAL DE JUSTIÇA. Brasil tem mais de 240 mil processos na área de Saúde. [on line] Disponível em: <http://www.cnj.jus.br/noticias/cnj/14096-brasil-tem-mais-de-240-mil-processos-naarea-de-saude>. 2011. Acesso em 10 jan. 2013.

Justiça em Números 2012. [on line] Disponível em: <http://www.cnj.jus.br/programas-de-a-a-z/eficiencia-modernizacao-etransparencia/pj-justica-em-numeros/relatorios>. 2012. Acesso em 4 jan. 2013.

Constituição da República Federativa do Brasil (1988). [on line] Disponível em: <http://www.planalto.gov.br/ccivil_03/constituicao/constituicao.htm>. 1988. Acesso em 5 fev. 2013.

DEFENSORIA PÚBLICA DA UNIÃO. Resolução no 13 de 25 de outubro de 2006. [on line] Disponível em: <http://www.dpu.gov.br/legislacao/ arquivos/pdf/2006/2006resolucao13.pdf>. 2006. Acesso em 10 jan. 2013. 
INSTITUTO DE PESQUISA ECONÔMICA APLICADA (IPEA). Nota Técnica: Custo e tempo do processo de execução fiscal promovido pela Procuradoria Geral da Fazenda Nacional. [on line] Disponível em: $<$ http://www.ipea.gov.br/agencia/images/stories/PDFs/nota_tecnica/111230_notatecni cadiest1.pdf>. 2011. Acesso em 5 dez. 2012.

. JUSTIÇA FEDERAL NO RIO GRANDE DO NORTE. Ação Civil Pública $n^{\circ}$ 0005798-63.2012.4.05.8400. [on line] Consulta processual disponível em: <http://www.jfrn.jus.br/>. 2012. Acesso em 12 dez. 2012.

. Lei no 1.060, de 5 de fevereiro de 1950. [on line] Disponível em: <http://www.planalto.gov.br/ccivil_03/leis/L1060.htm>. 1950. Acesso em 4 jan. 2013.

Lei no 5.869, de 11 de janeiro de 1973 (Código de Processo Civil. [on line] Disponível em: <http://www.planalto.gov.br/ccivil_03/leis/L5869.htm>. 1973. Acesso em 5 fev. 2013.

Lei no 8.080, de 19 de setembro de 1990. [on line] Disponível em: <http://www.planalto.gov.br/ccivil_03/leis/L8080.htm>. 1990. Acesso em 5 fev. 2013.

BRASIL. SUPREMO TRIBUNAL FEDERAL. Proposta de Súmula Vinculante $n^{\circ}$ 4. [on line] Disponível em: < http://www.stf.jus.br/portal/processo/ verProcessoAndamento.asp> (objeto de pesquisa: PSV 4). 2008. Acesso em $15 \mathrm{dez}$. 2012.

$\bar{J}_{\text {Julgado }} \cdot$ em 12/09/2000. [on Recurso Extraordinário 271.286/RS. <http://www.stf.jus.br/portal/jurisprudencia/listarJurisprudencia.asp?s1=\%28RE\%24\% 2ESCLA\%2E+E+271286\%2ENUME\%2E\%29+OU+\%28RE\%2EACMS\%2E+ADJ2+27 1286\%2EACMS\%2E\%29\&base=baseAcordaos\&url=http://tinyurl.com/ah6x5gl>. 2000. Acesso em 15 jan. 2013.

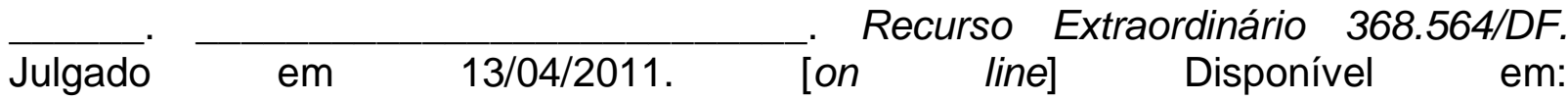
<http://www.stf.jus.br/portal/jurisprudencia/listarJurisprudencia.asp?s1=\%28368564\% 29\&base=baseAcordaos\&url=http://tinyurl.com/clwklxj>. 2011. Acesso em 15 jan. 2013.

$\overline{\text { line] }} \cdot \begin{array}{lll} & \text { Recurso Extraordinário 566.471/RN. [on } \\ <\text { http://www.stf.jus.br/portal/processo/ }\end{array}$ verProcessoAndamento.asp?incidente=2565078>. 2012. Acesso em 15 dez. 2012.

CRUZ E ALVES, Adler. A Atuação Cidadã da AGU na Redução da Litigiosidade Envolvendo o Instituto Nacional do Seguro Social: considerações acerca de instrumentos de ação da AGU capazes de promover o amplo reconhecimento de direitos sociais. In: BRASIL, AGU. Publicações da Escola da AGU: Trabalhos Vencedores do Concurso de Monografias da AGU em 2009-2010, 5(15):7-44, fev. 2012. ISSN 2236-4374. 
MACHADO, Felipe e DAIN, Sulamis. Direito e saúde: contribuições para o estudo da judicialização. In: ASENSI, Felipe e PINHEIRO, Ronseni (orgs.) Direito Sanitário, Rio de Janeiro: Elsevier, 2012, p. 463-489. ISBN 978-85-352-5111-1.

MARQUES, Onofre; MELO, Marilene e SANTOS, Alessandra. Ações judiciais no âmbito do sistema único de saúde do Brasil, bases legais e implicações: um estudo de caso em um tribunal da Região Sudeste. Revista de Direito Sanitário. [on line] Disponível em: <http://www.revistas.usp.br/rdisan/article/view/13236>. 2011. Acesso em 14 dez. 2012. ISSN 2316-9044.

MARQUES, Silvia e DALLARI, Sueli. Garantia do direito social à assistência farmacêutica no Estado de São Paulo. Revista de Saúde Pública. [on line] Disponível em: <http://www.revistas.usp.br/rsp/article/view/32199/34304>. 2007. Acesso em 10 dez. 2012. ISSN 1518-8787.

RIO GRANDE DO NORTE. DEFENSORIA PÚBLICA ESTADUAL. Programa SUS Mediado. [on line] Disponível em:<http://www.defensoria.rn.gov.br/ contentproducao/aplicacao/defensoria/imprensa/enviados/noticia_detalhe.asp?nCodig oNoticia=33763> . 2012. Acesso em 10 dez. 2012.

SOUZA, Luciane Moessa de. Meios consensuais de solução de conflitos envolvendo entes públicos: negociação, mediação e conciliação na esfera administrativa e judicial. Belo Horizonte: Fórum, 2012. ISBN 978-85-7700-549-9.

VENTURA, Miriam et al. Judicialização da saúde, acesso à justiça e a efetividade do direito à saúde. Physys: Revista de Saúde Coletiva. [on line] Disponível em: <http://www.scielo.br/scielo.php?script=sci_arttext\&pid=S0103-73312010000100006>. 2010. Acesso em 10 dez. 2012. ISSN 0103-7331. 